\title{
Validation Of Cariogram In Caries Prediction At Woman And Their Children 4 Years After Pregnancy - Longitudinal Randomized Control Study
}

Olivera Dolic ( $\sim$ olivera.dolic@med.unibl.org) Univerzitet u Banjoj Luci Medicinski Fakultet https://orcid.org/0000-0002-1651-6701

Marija Obradovic

Univerzitet u Banjoj Luci Medicinski Fakultet

Zeljka Kojic

Univerzitet u Banjoj Luci Medicinski Fakultet

Natasa Trtic

Univerzitet u Banjoj Luci Medicinski Fakultet

Slava Sukara

Univerzitet u Banjoj Luci Medicinski Fakultet

Natasa Knezevic

Univerzitet u Banjoj Luci Medicinski Fakultet

Valentina Veselinovic

Univerzitet u Banjoj Luci Medicinski Fakultet

Research article

Keywords: Early childhood caries, Cariogram, pregnant women, Sensitivity, Specificity, Longitudinal study

Posted Date: August 28th, 2019

DOI: https://doi.org/10.21203/rs.2.13633/v1

License: (c) (1) This work is licensed under a Creative Commons Attribution 4.0 International License.

Read Full License 


\section{Abstract}

Aim To evaluate Cariogram caries risk assessment during pregnancy with DMFT/dmft incidence at mother and children 4-years later.Background To validate baseline caries risk classifications according to Cariogram for pregnant women with the actual DMFT development after 4-year and the second aim was to validate assessed caries risk at pregnant women according to Cariogram with caries development at their children four years after.

Methods The study population consisted of 96 pregnant women (average age 27, 4 years at baseline) that completed clinical baseline examination and salivary tests. A caries risk assessment was made using Cariogram model and according to it, participants were divided into five risk groups. The follow-up study was initiated 4 years later and the 80 pairs of mother and children (from that pregnancy) were reexamined using the same procedure as did at baseline. An individual caries risk profile and DMFT/dmft incidence were made for each woman and child. Sensitivity, specificity, positive predictive value (PPV) and negative predictive value (NPV) for two cut-off were calculated to express the outcome.

Results There was a strong association between the risk categories of pregnant women and their offspring as well as between caries development in children and the Cariogram risk categories of their mother in pregnancy. Sensitivity and PPV for new DMFT $(\triangle D M F T>0)$ over 4 years for women was high $(>80 \%)$ for those participants assessed with 0-60\% "chance to avoid caries", as well as diagnostic accuracy $(74.00 \%)$. High specificity $(91.00 \%)$, very high PPV (95.00\%) and clinically useful values according to Youden's index (0.53) were obtained for moderate and two lowest risk groups for $\mathrm{dmft}$ in children.

Conclusions With the limits of this study, Cariogram was valid and highly predictive in caries risk assessment in children based on caries risk assessment of their mother in pregnancy. The Cariogram model can be useful tool for caries prediction in both groups of woman and their children based on caries risk assessment during pregnancy.

\section{Background}

Caries is multifactorial disease and it is determined by the interaction of different microbial, genetic, immunological, behavioral, as well as environmental factors. The most common chronic disease in childhood is early childhood caries (EEC) that occurs in children below 71 months of age. It still remains huge problem both in developed and developing countries [1, 2]. Many studies have demonstrated the association of MS (mutans streptococci) with ECC [3-6]. A systematic reviews confirmed that maternal factors influence bacterial acquisition, whereas colonization was mostly mediated by oral health and feeding habits [7, 8] during the first year of life. Cross-sectional [9] and longitudinal [10] studies have corroborated the association between parental dental status and offspring caries.

Identifying children at greatest risk of caries in order to design appropriate preventive activity has been a goal of the dental profession for many years. It is expected that multiple factors, combined on an 
appropriate scale and accounted for possible interactions may improve the prediction of caries risk. The challenge is to develop really effective model for predicting caries risk. The Cariogram ${ }^{\circledR}$, an algorithm based software, assesses an individual's caries risk profile and contains many "if "conditions - it can operate with 5 million combinations of caries related factors [11].The program offers recommendations for targeted preventive measures that should be implemented to avoid the formation of new caries lesions [12,13].

Cariogram has been used to assess the caries risk profile of schoolchildren $[14,15]$, teenagers, young adults [16-20], orthodontic [21] and elderly patients [22]. Some studies used Cariogram to assess caries risk profile of preschool children [23-28]. In a previous study, we presented that Cariogram can be useful toll in caries risk assessment and identification of significant caries risk factors in a group of pregnant woman [29], but to our knowledge, there are no studies that used Cariogram of pregnant women in offspring risk profile prediction.

Therefore, the aim of this study was to evaluate baseline caries risk assessment according to Cariogram during pregnancy with the DMFT/dmft development at mother and children after 4-years.

The null hypothesis was that children's caries risk profiles by Cariogram is associated with caries risk profiles (by Cariogram) of their mothers during pregnancy.

\section{Methods}

\section{Study group}

This longitudinal study was performed as follow up of randomized control study previously presented by Dolic and al [29].The study population consisted of 96 pregnant women who were between 20 and 42 years old (average age 27, 4 years) at the start of the study. They lived in different socio-economic areas of the city of Banja Luka, Bosnia and Herzegovina. They were recruited at Pregnancy counseling center at Public Hospital Banja Luka. Among the 213 pregnant women who were initially eligible, 96 fulfilled the inclusion criteria and were included in the study. The study included only pregnant women a) who were in last trimester of a normal, single fetus pregnancy, b) who didn't have high-risk pregnancies, C) who didn't have previous medical conditions, pregnancy complications, or pregnancy-related issues that required hospitalization, d) who did not have any chronic disease, e) who had not taken antibiotics or other drugs during pregnancy, f) who gave their written consent to participate in research.

The follow-up study was initiated 4 years later and the mother and their children (from that pregnancy) were re-examined by the same examiner, using the same procedure as that followed at baseline. The follow-up sample included 80 pairs of mother-child ( $83,33 \%$ recall rate), with 16 participants dropout- 10 did not want to participate in the follow up study and 6 had moved from the area.

In Banja Luka, pregnant women and children up to the age of 15 have access to free and regular dental care at public dental clinics. At baseline and follow-up the women were given detailed written and verbal 
information about the outline of the study, and they signed an informed consent for themselves and their children. During the study period, the participants were not informed about any result and they received regular dental care. All the participants were residents in areas with low natural fluoride content in the drinking water supply $(<0.30 \mathrm{mg} / \mathrm{l})$.

The research has been conducted in full accordance with the 1964 Helsinki declaration and its later amendments or comparable ethical standards and ethical approval for the study was obtained from The Research Committee of Faculty of Medicine, University of Banja Luka.

\section{Clinical examination}

The study consisted of five steps: a questionnaire, interview, clinical examination, saliva sampling, and assess of caries risk using the Cariogram. The questionnaire contained questions about: general health and medication, diet and oral hygiene habits including tooth brushing frequency and the use of fluoride.

All examinations were performed by one trained and calibrated examiner in the morning, between the meals and at least one hour after a meal and after teeth brushing. A plane mirror, WHO-CPI probe and air syringe were used in the clinical visual-tactile examination following WHO criteria [26]. Clearly visible lesions with cavities on tooth surfaces were classified as dental caries (i.e.d3-level cavities), whereas changes in transparency, initial enamel demineralization with intact surfaces and no cavitation were noted as intact teeth. The teeth were not professionally cleaned and no radiographs were taken. Caries prevalence was registered at the Decayed-Missed-Filled-Teeth (DMFT) level. The oral hygiene and oral biofilm amount were estimated using a mirror and periodontal probe in accordance with the Sillness and Löe plaque index.

Saliva sampling consisted of: measurement of the saliva secretion rate, measurements of saliva buffer capacity using a Dentobuff ${ }^{\circledR}$ Strip test, measurements of mutans streptococci in the saliva using a Dentocult ${ }^{\circledR}$ SM Strip mutans test and measurements of lactobacilli in the saliva using a Dentocult ${ }^{\circledR}$ LB test according to the manual of the manufacturer. Paraffin-stimulated whole saliva was collected for 5 minutes and the secretion rate was expressed as $\mathrm{ml} / \mathrm{min}$. Buffer capacity was categorized as high, medium or low. The density of colonies (Streptococcus mutans and Lactobacillus) was compared with a chart provided by the manufacturer (Orion Diagnostica, Finland).

Data for the computerized caries risk assessment were entered into the Cariogram to obtain an individual caries risk profile. The following five Cariogram categories were used: "very high risk" $=0-20 \%$ chance to avoid caries; "high risk" $=21-40 \%$ chance to avoid caries; "moderate risk" $=41-60 \%$ chance to avoid caries; "low risk" $=61-80 \%$ chance to avoid caries; and "very low risk" $=81-100 \%$ chance to avoid caries.

The patient and the patient's ordinary dental team were not informed about calculated Cariogram risk category. The patient's regular dental team was responsible for preventive and restorative dental care during the entire study period.

Statistical methods 
All data were processed with the SPSS software (version 16.0, Chicago III., USA). $\chi 2$ test of contingency was used to compare the difference between groups. Parametric ANOVA and Student's test for independent samples (if the difference variance observed characteristics were not statistically significant) and nonparametric Mann-Whitney test (if the difference in the variance of the observed characteristics statistically significant) were used to compare the mean values of the characteristics. Sensitivity, specificity, positive predictive value (PPV) and negative predictive value (NPV) were calculated from two-by-two tables. $P$ values less than 0.05 were considered as statistically significant.

\section{Results}

Risk categories for children in regard to risk categories of their mother during pregnancy are shown in Figure 1. The results displayed that $85.00 \%(n=68)$ of the children were in the same risk category as their mother during pregnancy (at baseline). A higher-risk category then their mother during pregnancy had $10 \%(n=8)$ of children. Decreased risk than their mother during pregnancy had only $5 \%(n=4)$ of children $(P<0.001)$.

Table 1. Cross tabulation of DMFT incidence at 4-year-follow up with overall caries risk level predicted by Cariogram at baseline 


\begin{tabular}{|c|c|c|c|c|c|c|c|c|c|}
\hline \multirow{2}{*}{$\begin{array}{c}\text { Baseline risk } \\
\text { category by } \\
\text { Cariogram } \\
\text { of pregnant } \\
\text { women }\end{array}$} & \multicolumn{2}{|c|}{$\begin{array}{c}\text { No of } \\
\text { pregnant } \\
\text { women }\end{array}$} & \multicolumn{2}{|c|}{$\begin{array}{c}\text { No of pregnant } \\
\text { women with } \\
\Delta \mathrm{DMFT}>0\end{array}$} & \multirow{2}{*}{$\begin{array}{l}\text { Baseline } \\
\text { DMFT } \\
\text { (Mean, } \\
\text { SD) }\end{array}$} & \multirow{2}{*}{$\begin{array}{c}\text { Follow- } \\
\text { up } \\
\text { DMFT } \\
\text { (Mean, } \\
\text { SD) }\end{array}$} & \multirow[t]{2}{*}{$\begin{array}{c}\text { Mean } \\
\text { DMFT } \\
\text { increment }\end{array}$} & \multirow{2}{*}{$\begin{array}{c}95 \% \text { CI } \\
\text { *for mean } \\
\text { DMFTincrement }\end{array}$} & \multirow{2}{*}{$\begin{array}{c}\mathrm{p} \\
\text { value }\end{array}$} \\
\hline & $\mathrm{n}$ & $\%$ & $\mathbf{n}$ & $\%$ & & & & & \\
\hline Very high & 13 & 16.25 & 9 & 69.23 & $\begin{array}{c}20.15 \pm \\
3.67\end{array}$ & $\begin{array}{l}22.17 \\
\pm 4.00\end{array}$ & $\begin{array}{c}2.92 \pm \\
2.02\end{array}$ & $1.70-4.14$ & 0.000 \\
\hline High & 24 & 30.00 & 20 & 83.33 & $\begin{array}{c}16.83 \pm \\
2.63\end{array}$ & $\begin{array}{r}18.67 \\
\pm 2.59\end{array}$ & $\begin{array}{c}1.83 \pm \\
1.24\end{array}$ & $1.31-2.36$ & 0.000 \\
\hline Moderate & 18 & 22.50 & 15 & 83.33 & $\begin{array}{c}15.28 \pm \\
3.91\end{array}$ & $\begin{array}{r}16.11 \\
\pm 3.53\end{array}$ & $\begin{array}{c}1.44 \pm \\
1.34\end{array}$ & $0.78-2.11$ & 0.000 \\
\hline Low & 13 & 16.25 & 5 & 38.46 & $\begin{array}{c}13.77 \pm \\
2.78\end{array}$ & $\begin{array}{r}14.67 \\
\pm 3.68\end{array}$ & $\begin{array}{c}1.08 \pm \\
1.71\end{array}$ & $0.05-2.11$ & 0.042 \\
\hline Very low & 12 & 15.00 & 5 & 41.67 & $\begin{array}{c}11.92 \pm \\
3.50\end{array}$ & $\begin{array}{r}12.10 \\
\pm 4.09\end{array}$ & $\begin{array}{c}0.75 \pm \\
1.22\end{array}$ & $0.02-1.52$ & 0.056 \\
\hline Total & 80 & 100.00 & 54 & 68.00 & $\begin{array}{c}15.79 \pm \\
4.16\end{array}$ & $\begin{array}{r}17.43 \\
\pm 4.74\end{array}$ & $\begin{array}{c}1.64 \pm \\
1.60\end{array}$ & $1.28-1.99$ & 0.000 \\
\hline
\end{tabular}

The distribution of women with new DMFT in relation to the baseline Cariogram risk category, mean DMFT at baseline and 4 years follow up, as well as mean DMFT increment are shown in Table 1. The positive relationship was statistically significant and the women in very high and high risk categories had more DMFT than those in very low risk group $(p<0.05)$. The difference in mean DMFT at the baseline and follow up for very low group was not statistically significant.

Sensitivity, specificity and predictive values for new DMFT $(\triangle \mathrm{DMFT}>0)$ over 4 years for women are displayed in Table 2. Sensitivity (Se) and specificity (Sp) of the Cariogram were compared at two cut-off points. The moderate risk group was combined with the low risk and very low group and it was taken as cut off 1 . As cut off 2 , it was combined the moderate, the high and very high risk groups. Sensitivity and PPV was high ( $>80 \%)$ for cut-off 2 , for those assessed with $0-60 \%$ "chance to avoid caries", as well as diagnostic accuracy $(74.00 \%)$. When the moderate risk combined with the two lowest risk groups sensitivity, diagnostic accuracy and NPV were lower than $60 \%$. 
Table 2. Sensitivity, specificity and predictive values for new DMFT ( $\Delta$ DMFT $>0$ ) over 4years for women

\begin{tabular}{|c|c|c|c|c|c|c|c|c|}
\hline $\begin{array}{c}\text { Cariogram (for women) } \\
\text { cut-off }\end{array}$ & $\mathrm{Se}^{\mathrm{a}}$ & $\mathrm{Sp}^{\mathrm{b}}$ & $\mathrm{PPV}^{\mathrm{c}}$ & $\mathrm{NPV}^{\mathrm{c}}$ & $\begin{array}{c}\text { Youden } \\
\text { index }^{\mathrm{d}}\end{array}$ & $\begin{array}{c}\text { Diagnostic } \\
\text { accuracy }\end{array}$ & LR + & LR - \\
\hline Cut-off 1 & 54.0 & 69.0 & 78.0 & 42.0 & 0.23 & 59.0 & 1.7453 & 0.6687 \\
\hline Cut-off 2 & 81.0 & 58.0 & 80.0 & 60.0 & 0.39 & 74.0 & 1.9259 & 0.3209 \\
\hline
\end{tabular}

aSensitivity

bSpecificity

$\mathrm{cPPV}=$ positive predictive value; $\mathrm{NPV}=$ negative predictive value.

$\mathrm{dJ}=$ sensitivity + specificity -1 .

LR-Likelihood ratio

The distribution of children with $\mathrm{dmft}$ in relation to the Cariogram risk category of their mother in pregnancy and mean dmft of children are shown in Table 3. The children of high and very high risk mothers in pregnancy had more DMFT than those in very low risk group $(p<0.05)$.

Table 3. Distribution of children with dmft in relation to the Cariogram risk category of their mother in pregnancy 


\begin{tabular}{|c|c|c|c|c|c|c|c|c|c|c|}
\hline \multirow[t]{2}{*}{$\begin{array}{c}\text { Baseline risk } \\
\text { category of } \\
\text { pregnant women }\end{array}$} & \multicolumn{2}{|c|}{$\begin{array}{l}\text { No of } \\
\text { pregnant } \\
\text { women }\end{array}$} & \multicolumn{2}{|c|}{$\begin{array}{c}\text { Risk } \\
\text { category of } \\
\text { children }\end{array}$} & \multicolumn{2}{|c|}{$\begin{array}{c}\text { No of children } \\
\text { with } \Delta \mathrm{dmft}= \\
0\end{array}$} & \multicolumn{2}{|c|}{$\begin{array}{l}\text { No of children } \\
\text { with } \Delta \mathrm{dmft}>0\end{array}$} & \multirow[t]{2}{*}{$\begin{array}{l}\text { dmft of } \\
\text { children } \\
\text { (Mean, SD) }\end{array}$} & \multirow{2}{*}{$\begin{array}{l}\text { Chi- } \\
\text { square } \\
p \\
\text { value }\end{array}$} \\
\hline & $\mathbf{n}$ & $\%$ & $\mathbf{n}$ & $\%$ & $\mathbf{n}$ & $\%$ & $\mathbf{n}$ & $\%$ & & \\
\hline Very high & 13 & 16.25 & 18 & 22.50 & 0 & 0.00 & 13 & 100.00 & $10.94 \pm 3.96$ & 0.000 \\
\hline High & 24 & 30.00 & 21 & 26.25 & 2 & 8.33 & 22 & 91.67 & $5.90 \pm 2.84$ & \\
\hline Moderate & 18 & 22.50 & 15 & 18.75 & 6 & 33.33 & 12 & 66.67 & $3.73 \pm 2.71$ & \\
\hline Low & 13 & 16.25 & 13 & 16.25 & 3 & 23.08 & 10 & 76.92 & $1.00 \pm 0.91$ & \\
\hline Very low & 12 & 15.00 & 13 & 16.25 & 12 & 100.00 & 0 & 0.00 & $0.08 \pm 0.28$ & \\
\hline Total & 80 & 100.00 & 80 & 100.00 & 23 & 28.75 & 57 & 71.25 & $4.89 \pm 4.70$ & \\
\hline
\end{tabular}

Sensitivity, specificity and predictive values for $\mathrm{dmft}(\triangle \mathrm{DMFT}>0)$ in children are displayed in Table 4 . Sensitivity (Se) and specificity (Sp) of the baseline Cariogram (pregnant women) were compared at two cut-off points on the same way like for women. The moderate risk group was combined with the low risk and very low group and it was taken as cut off 1 . As cut off 2 , it was combined the moderate, the high and very high risk groups. High specificity (91.00\%), very high PPV (95.00\%) and clinically useful values according to Youden's index (0.53) were obtained for cut-off 1 (moderate and two lowest risk groups). When the moderate risk combined with the two lowest risk groups sensitivity and PPV were higher than $82 \%$.

Table 4. Sensitivity, specificity and predictive values for $\mathrm{dmft}(\Delta \mathrm{dmft}>0)$ in children

\begin{tabular}{|c|c|c|c|c|c|c|c|c|}
\hline $\begin{array}{c}\text { Cariogram (for women) } \\
\text { cut-off }\end{array}$ & $\mathrm{Se}^{\mathrm{a}}$ & $\mathrm{Sp}^{\mathrm{b}}$ & $\mathrm{PPV}^{\mathrm{c}}$ & $\mathrm{NPV}^{\mathrm{c}}$ & $\begin{array}{c}\text { Youden- } \\
\text { index }^{\mathrm{d}}\end{array}$ & $\begin{array}{c}\text { Diagnostic } \\
\text { accuracy }\end{array}$ & LR + & LR - \\
\hline Cut-off 1 & 61.0 & 91.0 & 95.0 & 49.0 & 0.53 & 70.0 & 7.0614 & 0.4227 \\
\hline Cut-off 2 & 82.0 & 65.0 & 85.0 & 60.0 & 0.48 & 78.0 & 2.3706 & 0.239 \\
\hline
\end{tabular}

aSensitivity

bSpecificity

$\mathrm{cPPV}=$ positive predictive value $\mathrm{NPV}=$ negative predictive value

$\mathrm{d} \mathrm{J}=$ sensitivity + specificity -1 . 


\section{Discussion}

Oral health has been an important aspect of adult, as well as, children well-being and quality of life. Untreated dental caries associated with discomfort/pain can affect weight gain, normal growth and child's development, therefore preventive and therapeutic measures must be based on the most current scientific and clinical knowledge available[2]. Despite the fact that the Health Insurance Fund of Bosnia and Herzegovina covers full costs of dental care for children younger than 15-years, the ECC prevalence is extremely high and the most of the lesions are untreated [2]. In countries like Bosnia and Herzegovina, with high caries prevalence, caries risk assessment is very important, but there is only data about caries risk assessment in the 12-years-old children [18] and pregnant women [29].

In the present study, the majority of participants (women and children) were at high risk of caries according to Cariogram. It was found that $48.75 \%$ of 4 -years-old children are in a very high and high risk group. Garg et al. also showed highest percentage of 5-years-old children $(66.2 \%)$ developed new caries lesions in the category of high risk group [28]. Stecksen-Blickset al. investigated the existing caries risk factors in 2-years- old children and displayed that $51 \%$ of the sample had a low chance (or very high risk) of avoiding caries in the future [23]. Study concerning Greek (2-6 years old) preschool children reported the highest number of patients in a moderate caries risk group (65\%) and only $29 \%$ in a high risk group [25]. The study conducted in Macedonia among 4-5-years-old children, showed that $55.10 \%$ children had a moderate dental caries risk and $40.82 \%$ children had a high dental caries risk according to Cariogram [27].

It is very difficult to compare the results of Cariogram for pregnant women in the present study, as no studies were conducted pregnant women and their offspring. Study performed in children and adult populations in Turkey showed that the majority of their participants had a high risk for caries, while Celik et al. reported the majority Turkish adults (20-21 years old) with medium and low caries risk ( $33 \%$ and $24 \%$, respectively) $[30,31]$. In the study of Sonbul et al. the prevalence rates of caries risk in adults with several dental restorations in Saudi Arabia were high [32].

In the early caries risk assessment by Cariogram studies, researchers identified and measured various caries related factors and correlated them to the current caries status of the individual, i.e. after 1-3 years, in longitudinal studies. Data obtained from these studies often used simple correlation for analyses. Stamm et al. state that useful risk assessment program should be one with high simplicity, sensitivity, and specificity [33]. Often, it may be very impractical to be achieved simultaneously simplicity and accuracy. But in more recent years, sensitivity/specificity, predictive powers and Youden's index have been applied for validation in Cariogram studies [34-36].

The principle of sensitivity / specificity is to use a specific cut-off value for the factor under investigation and to define a specific outcome of the test. In present study, the relatively high negative predictive values 
are found for the both cut-off and both aims: (1) to validate baseline caries risk classifications according to Cariogram with the actual caries development over a 4-year period in a group of women; (2) validate (baseline?) caries risk classification of pregnant women according to Cariogram with the offspring actual caries development after 4 years. The similar results are found in Holgerson longitudinal study in Sweden, which showed that validation of a modified Cariogram in 2-years-old preschool children resulted in high sensitivity for future caries 5 years later, but the method lacked precision and accuracy [24].

The predictive ability of Cariogram for pregnant women at both cut-off points had specificity lower than $70 \%$, which may categorized in high-risk group some individuals with actual low caries risk and unnecessary preventive measures may be taken. But, on the other hand, according to PPV $(>78 \%)$ in both cut-offs, it can be seen that a higher percentage of patients will actually develop caries. PPV is even higher ( $95 \%$-cut off $1,85 \%$-cut off 2 ) for a possibility of caries developing in offspring if pregnant women is in the higher risk of caries according Cariogram.

In recent studies from Hong Kong, the results showed that the Cariogram for preschool children generally exhibited a higher accuracy $[26,37]$. In the present study, for validation of caries experience in children using Cariogram model of their mothers during pregnancy, accuracy was higher than $70 \%$ for both cutoffs. Also, validation used in this study obtained clinically useful values according to Youden's index, when moderate and two lowest risk groups have combined.

\section{Conclusions}

With the limits of this study, Cariogram was valid and highly predictive in caries risk assessment in children based on caries risk assessment of their mother in pregnancy. The Cariogram model can be useful tool for caries prediction in both groups of woman and their children based on caries risk assessment during pregnancy.

\section{Declarations}

\section{ACKNOWLEDGMENTS}

This research was supported by the Ministry of Science and Technology of the Republic of Srpska, Bosnia and Herzegovina. Also, we are grateful to Orion Diagnostica, Finland, for making this research possible, and to Bojan Stanković for statistical analysis.

\section{Competing interests}

The authors declare that they have no competing interests. The authors alone are responsible for the content and writing of the paper.

\section{Authors' contributions}


OD: conceptualized and designed study, supervised and evaluated the data collection, critically reviewed the manuscript. OD and $\mathrm{MO}$ have made substantial contributions to statistical analyses and interpretation of the results. MO, ZK, NT, SS, NK, VV critically reviewed the manuscript. All authors have contributed to and read the final draft. All authors read and approved the final manuscript.

\section{Ethics approval and consent to participate}

Ethical approval for the study was obtained from The Research Committee of Faculty of Medicine, University of Banja Luka. All participants gave their written consent to participate in research.

\section{References}

1. Çolak H, Dülgergil ÇT, Dalli M, Hamidi MM. Early childhood caries update: A review of causes, diagnoses, and treatments. J Nat ScBiol Med. 2013;4:29-38.

2. Obradovic M, Dolic O, Sukara S. Caries Prevalence among 24 to 71-Month Old Children from Banja Luka. Balk J Dent Med. 2016;20:168-171.

3. Ramamurthy PH, Swamy HS, Bennete F, Rohini M, Nagarathnamma T. Relationship between severeearly childhood caries, salivary mutans streptococci, and lactobacilli in preschool children of low socioeconomic status in Bengaluru city. J Indian SocPedodPrev Dent 2014;32:44-7.

4. Seow WK, Clifford H, Battistutta D, Morawska A, Holcombe T. Case-control study of early childhood caries in Australia. Caries Res 2009; 43: 25-35.

5. Tankkunnasombut S, Youcharoen K, Wisuttisak W, Vichayanrat S, Tiranathanagul S. Early colonization of mutans streptococci in 2- to 36-month-old Thai children. Pediatr Dent 2009;31:4751.

6. Parisotto TM, Steiner-Oliveira C, Duque C, Peres RCR, Rodrigues LKA, Nobre-dos-Santos M. Relationship among microbiological composition and presence of dental plaque, sugar exposure, social factors and different stages of early childhood caries. Arch Oral Biol 2010;55:365-373.

7. Leong PM, Gussy MG, Barrow SWL, de Silva-Sanigorski A, Waters E. A systematic review of risk factors during first year of life for early childhood caries. International Journal of Paediatric Dentistry. 2013;23 (4):235-250.

8. Obradović M, Dolic O, Vojinovic J, Sukara S. Association between feeding habits and severe - early childhood caries in children up to 24 month old. Serbian Dental Journal. 2016;63(3):117-124.

9. Dye BA, Vargas CM, Lee JJ, Magder L, Tinanoff N. Assessing the relationship between children's oral health status and that of their mothers. J Am Dent Assoc. 2011;142:173-183.

10. Shearer DM, Thomson WM, Caspi A, Moffitt TE, Broadbent JM, Poulton R. Family history and oral health: findings from the Dunedin Study. Community Dent Oral Epidemiol. 2012;40:105-115.

11. Petersson GH, Twetman S, Bratthall D. Evaluation of a computer program for caries risk assessment in schoolchildren. Caries Res. 2002;36:327-40.

12. Petersson GH. Assessing caries risk using the Cariogram model. Swe Dent J Supp. 2003;158:1-65. 
13. Twetman S, Petersson GH, Bratthall D. Caries risk assessment as a predictor of metabolic control in young Type I diabetics. Diabet Med 2005;22:312-5.

14. Campus G, Cagetti MG, Sale S, Carta G, Lingstrom P. Cariogram validity in schoolchildren: a two-year follow-up study. Caries Res. 2012;46(1):16-22.

15. Petersson GH, Isberg PE, Twetman S. Caries risk profiles in schoolchildren over 2 years assessed by Cariogram.Int J Paediatr Dent. 2010; 20:341-6.

16. Cabral RN, Hilgert LA, Faber J, Leal SC. Caries risk assessment in schoolchildren - a form based on Cariogram ${ }^{\circledR}$ software. J Appl Oral Sci. 2014;22(5):397-402.

17. Hebbal M, Ankola A, Metgud S. Caries risk profile of 12 year old school children in an Indian city using Cariogram. Med Oral Patol Oral Cir Bucal. 2012 Nov 1;17 (6):e1054-61.

18. Zukanovic A, Kobaslija S, Ganibegovic M. Caries risk assessment in Bosnian children using Cariogram computer model. Int Dent J. 2007;57:177-83.

19. Campus G, Cagetti MG, Sacco G, Benedetti G, Strohmenger L, Lingström P. Caries risk profiles in Sardinian schoolchildren using Cariogram. Acta Odontol Scand. 2009;67:146-152. [

20. Petersson GH. Ericson E, Isberg PE, Twetman S. Caries risk assessment in young adults using Public Dental Service guidelines and the Cariogram- a comparative study. Acta Odontol Scand. 2013;71(34):534-40.

21. Al Mulla A, Kharsa S, Kjellberg H, Birkhed D. The use of Cariogram to evaluate caries-risk profiles in orthodontic patients. World J Orthod 2010;11:160-167.

22. Petersson GH, Fure S, Bratthall D. Evaluation of a computer-based caries risk assessment program in an elderly group of individuals. Acta Odontol Scand. 2003; 61:165-70.

23. Stecksen-Blicks C, Holgerson PL and Twetman S. Caries risk profiles in two-year-old children from northern Sweden. Oral Health Prev Dent. 2007;5(3):215-221.

24. Holgerson PL, Twetman S, Stecksèn-Blicks $C$. Validation of an age-modified caries risk assessment program (Cariogram) in preschool children. Acta Odontologica 2009;67(2):106-12.

25. Kavvadia K ,Agouropoulos A. Caries risk profiles in 2- to 6-year-old Greek children using the Cariogram. Eur J Dent. 2012;6(4):415-421.

26. Gao X, Di Wu I, Lo EC, Chu CH, Hsu CY, Wong MC. Validity of caries risk assessment programmes in preschool children.Journal of dentistry. 2013 Sep 1;41(9):787-95.

27. Jakupi JA, Iljovska S, Naskova S, Pavlevska M, Nuhii N. Assessing the caries risk factor among children at age prom 4-5 using the cariogram program. International Journal of Scientific \& Engineering Research, 2015; 6(11):554-562.

28. Garg A, Madan M, Dua P, Saini S, Mangla R, Singhal P, Dupper A. Validating the Usage of Cariogram in 5-and 12-year-old School-going Children in Paonta Sahib, Himachal Pradesh, India: A 12-month Prospective Study. International journal of clinical pediatric dentistry. 2018;11(2):110.

29. Dolic O, Obradovic M, Kojic Z, SukaraS.Caries Risk Assessment in Pregnant Women Using Cariogram. Srp Arh Celok Lek. 2017;145(3-4):178-83. 
30. Gökalp SG, Dogan BG, Tekçiçek MT, Berberoglu A, Unlüer S. National survey of oral health status of children and adults in Turkey. Community Dent Health. 2010;27:12-7.

31. Celik EU, Gokay N, Ates M. Efficiency of caries risk assessment in young adults using Cariogram.Eur J Dent. 2012;6:270-9.

32. Sonbul H, Al-Otaibi M, Birkhed D. Risk profile of adults with several dental restorations using the Cariogram model. Acta Odontol Scand. 2008;66:351-7.

33. Stamm JW, Stewart PW, Bohannan HM, Disney JA, Graves RC, Abernathy JR. Risk assessment for oral diseases. Advances in dental research. 1991;5(1):4-17.

34. Dou L, Luo J, Fu X, Tang Y, Gao J, Yang D. The validity of caries risk assessment in young adults with past caries experience using a screening Cariogram model without saliva tests. International dental journal. 2018;68(4):221-226.

35. Petersson GH, Twetman S. Caries risk assessment in young adults: a 3 year validation of the Cariogram model. BMC oral health. 2015;15(1):17.

36. Sudhir KM, Kanupuru KK, Nusrath F, Embeti S, Chaitra NT. Validation of Cariogram as a Tool for Caries Risk Prediction Among 12-Year-Old Institutionalized Children-A Longitudinal Follow-up Study. 2017;16(4)e.1-8.

37. Gao X, Hsu CY, Loh T, Hwarng B, Koh D. Role of microbiological factors in predicting early childhood caries. Pediatr Dent. 2014;36:348-54.

\section{Figures}

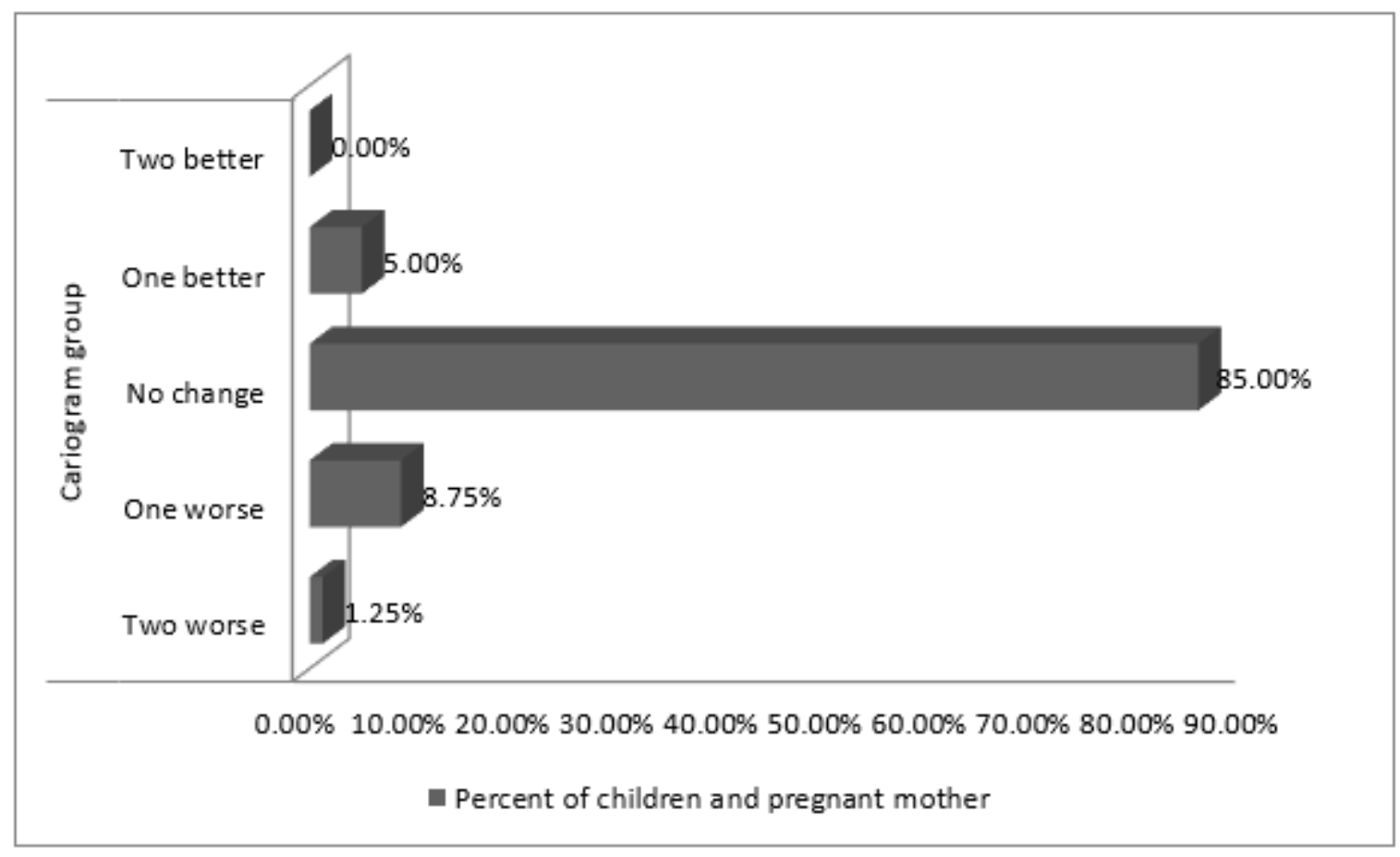

\section{Figure 1}


Risk categories for children in regard to risk categories of their mother during pregnancy 